\title{
ETHYMOLOGICAL ANALYSIS OF THE WORD BAKHSHI IN THE FOLKLOR STUDIES OF TURK PEOPLES
}

\author{
I. Zh. Juldashev \\ State Institute of Arts and Culture, Uzbekistan
}

\begin{abstract}
This article discusses the etymology of the concept of bakhshi, which is the name of a separate type of art, and the name of the singers who are engaged in the art of bakhshi, which is given considerable attention in Uzbekistan as a national value.
\end{abstract}

Keywords: Bakhshi; Source; Transcription; Festival; Etymology

\section{ЭТИМОАОГИЧЕСКИЙ АНААИЗ САОВА БАХШИ В ФОАЬКАОРИСТИКЕ ТЮРКСКИХ НАРОАОВ'}

\author{
И. Ж. Ю^Аашев
}

ГосуАарственный институт искусств и культуры, Узбекистан

Резюме: В Аанной статье рассматривается вопрос об этимологии понятия бахши, являющееся названием отАельного вида искусства, и наименованием певцов, которые занимаются искусством бахши, которому немаловажное внимание уделяется в Узбекистане как национальная ценность.

КАючовие слова: бахши; источник; транскрипция; фестиваль; этимология

Сегоння в нашей стране особое внимание улеляется искусству бахши, которое сохранилось как национальная ценность. Так 1 ноября 2018 гола было принято Постановление Презилента Республики Узбекистан «О провеАении межАународного фрестиваля искусства бахшил. На основе Аанного Постановления Министерство Культуры Республики Узбекистан, Акалемия Наук Республики Узбекистан и Хокимият Сурхандарьинского вилоята 5-10 апреля текущего года провели международный феестияль искусства бахши. В фестивале участвовали более 100 бахши, члены жюри и Аругие гости.

Заслуживает внимание тот фракт, что основным Аичным инициатором этого важного мероприятия яв^яется наш Презилент

1 В статье публикуются результаты доклала, представленного на конореренции $\mathrm{LCH} 2019$ 
Шавкат Миромонович Мирзиёев. Узбекистан считается родиной знаменитых бахши. Они воспевают Аревние богатые ценности, прошлое и настоящее, належлы и чаяния нашего нарола. В исполняемых бахши дастанах и терма отражаются такие качества нашего народа как патриотизм, благородство, гуманизм, ^юбовь и преданность к своей родине. Суть проведения такого межАународного фрестиваля огромна. По этому поводу на торжественной церемонии, посвященной открытию МежАународного фрестиваля изобразительных искусств Президент страны отмечал следующее: «Не секрет, что в настоящее сложное время в эпоху глобализации все более усиливается отрицательное влияние «массовой культуры» и шоубизнеса, которые превратились в срелство торговли, а фолььклору, который является источником всякой национальной культуры, уменьшается внимание и интерес. Ибо, если образно выразиться, фрольклор - это песня детства человечествал. Естественно, появляется этимология слова «бахши», являющееся названием отАельного виАа искусства, которому особое внимание улеляется в нашей республике. В $А$ анной статье автор раскрывает этимологию этого слова. Известно, что в истории узбекского письма своеобразное место занимает уйгурское письмо. Его основу состави^о согАийское письмо, которое в настоящее время называется уйгурским письмом, а в прошлом называ^ось монгольским письмом. Это письмо МахмуА Кашгари в своем произведении «САоварь тюркских наречий» назваА письмо потюркски, Алишер Навои в одном из произведений назвал тюркское письмо.

ПерсиАский поэт XIII века Пури Бахои Ажами в олном из стихотворений этого письма назваА уйгурским письмом, известный историк Ибн Арабшах в своем произвеАении «Ажойиб-улмакАур фои навоиби Таймур» назвал уйгурским письмом, а в произведении «Фокихат-ул-хулафоо» назва^ монгольским письмом. Аанное письмо в рукописи «Хибатул-хакойик», переписанный бахши АбАулразаком в Константинополе в 1480 году назва^ монгольским письмом (Sodikov, 2000: 117$)$.

В Аревних уйгурских письменных источниках человека, который занимался письмом называли бахши, битигчи, в науке, катиб. 
«Уйгурские письменные тексты дошли $\Delta$ о нас в орорме письма на отАельном мисте, тетради, книги, эпиграфрической графрики, Аоске, керамике и металмических предметах. Среди них основное место занимают книги, созданные в различные периоды истории тюрков, как нелелимая часть книговедения и определяет культурно-образовательное развитие тюркских народов. История тюркской книги в уйгурском письме появиАась уже тогАа, когАа применяли тюркско-согАй̆ский алфравит. С изобретением этого письма в свою очередь началась новая эра в тюркском книговедении. Ибо, в последующие периоды уйгурское письмо шире применяли в место орхун-енисейского письма, потому что оно было улобным и имело большие палеографрические возможности. А также рукописи уйгурского письма были более совершенны в техническом отношении» (р. 125). И это Аоказывает, что древнее тюркское книгопечатание и раньше прохолило своеобразные этапы.

В источниках отмечается, что $\Delta о$ «XVI века во Аворцах уйгурских шахов работали писари и их называли бахши») (Sherbak, 1962: 34) Как отмечал крупный языковеА Евгений Амитриевич Поливанов (1891-1938), «слово бахши в корне китайского происхожАения, его китайская фрорма «пак-ши» (в современном Китайском языке «бо-ши») и в тюркский язык это слово вошло через монгольский язык. Это китайское слово служило источником А^я САов «хакасе/хакуси» на японском языке») (Polivanov, 1922: 119). В «этимологическом словаре тюркского языка» приводится следующее сведение: «От китайского слова пак-ши происхолит бахши бакши (также произносится как по-ши, что означает: учитель, писатель, писарь). Это слово в АнаАули тюрки реАко применялось, его в основном употребляли тюрки шаманской веры, которое применялось по отношению человека, который управля^ свальбами». В Азиатском тюрки звук «п» произносится как «б». Поэтому с^ово по-Си произносится бо-си, баски, бакши. Китайское произношение этого слова применялось в различных Аиалектах. «В санскрите этого слова произносили бхикси, помонгольски - бакши» (Eyuboğlu, 1995: 68) А также в «Аревнетюркском словаре» отмечается, что табибов или ^екарей также называли отачи бакси. 3Аесь слово отачи образован Аобавлением слову «от» окончания амак, в результате появи^ось С^ово «отамак», что означало «озАарав^ивать» 
(Ancient Turkish dictionary, 1969: 373) В Аревности это слово означало «^екаря который ^ечи^ ^юдей разными травами» (Ancient Turkish dictionary, 1969: 516). В современном узбекском языке нет слово отачи. ОАнако это слово есть современном тюркском языке и она означает «отамак-^ечить больного ^екарствами; отаси-хаким, ^екарь» (Turkish dictionary, 1988: 1120). В источнике «Аттух фратуз закияту фри^^угатит туркия» указывается, что слово отачи употребляется в значении «табиб» ^екарь (Attuhfatuz, 1968: 81). А также в «С^оваре тюркских наречий» Кашгари отмечается, что слово отачи употребляется в значении «табиб» ^екарь (Koshgariy, 1960: 71).

Профрессор Э.Р. Тенишев отмечает, что лексема бахсе в восточном диалекте уйгурского языка означает «бахши», «табиб», «шаман», а также в Аоланском Аиалекте уйгурского языка означает «афрсунгар» (колАун), «фролбин» (гаАалка), в аксуйском Аиалекте означает вакси, (человек, который охотится с помошью птицамиохотниками), в калигарском и яркендском Аиалектах бакси (человек, который ^ечит ко^АОвством); в Аревних уйгурских памятниках это слово означает «устоз» (учитель), «шогирд» (ученик). А также ученый указывает, что ^ексические формы боши, боси, бакши заимствованы с китайского языка (Tenishev, 1990: 22). В Аругом источнике приводятся варианты бахши, бахси, пахси, паши, и утвержАается, что они связаны со словом «пак-СИ» и относятся К памятникам, написанным брохманским письмом (Gabain, 1974: 326). Известно, что в связи с широким распространением будлизма «Народы центральный Азии (в частности тухри и тюрки) в определенное время пользовались инАийским письмом (брахма). Известно памятники, которые написаны на этом письме (Sodikov, 2000: 148). По мнению В. В. БартольАа, в Восточном Туркестане лексема бахши (санскрит - бхишки) применена по отношению уйгурским писарям и будАистским монахам, которые жили среАи уйгуров.

В государстве монголов слово бахши означал «Котиб» (секретарь), «маъмур» (алминистратор) (Sultanov, 1987: 412). А также «секретарей, которые не знали персилский язык называли бахши" (Bartold, 1990: 53) По мнению А. К. Боровкова, в XII -XIII веках в уйгурском книгопечатании Восточного тюрка важное место занимали уйгурские 
секретари - бахши. Они в основном работали в офрициальных канцеляриях (Borovkov, 1963: 21).

Ао начала XVI века во Аворцах правителей средней Азии, в частности во Аворцах Темуридов работали писари, которые писали поуйгурски на уйгурском алфравите и по отношению к ним также употреблен термин бахши. В. В. БартольА утвержАает, что бахши имели огромный авторитет во Аворце Чигатайский ханов, им Аоверили написать исторические летописи (Bartold, 1990: 54). В частности, уйгурские бахши на уйгурском языке в стихотворной фрорме написали произведение "История хана" о военных походах полководца Амира Темура. Это произвеление стало основным источником при создании произведений Шарафудлин Али Язди "Зафрарнома" ("^етопись побел"), Аблумлох бин Мухаммал бин А^и Насрул^аха "Зублат алaсар". В научной митературе утвержАается, что бы^ использован уйгурский алфавит при написании Аокументаций и переписке с зарубежными странами в эпоху правления Темуридов. В частности, этому может служить примером послание темурила Абу Саила Узуну Хасану 10 октября 1468 гола. Это письмо в настоящее время хранится в музее-библиотеке в Константинополе. В 1940 голу А.Н. Курат изАал оригинал Аокумента с транскрипцией и историко-оилософиическим обзором (Sultanov, 1987: 483-484).

С^овом, «в эпоху ислама, особенно в XIV- XV века в культурной среде Моверауннахра, Хорасана, Онодули книгопечатание на уйгурском письме быстро развивалось и послеАний раз на этой земле АостигАо своего пика. В те времена в таких культурных центрах, как Яза, Герат, СамарканА, Константинополь и Аругих возникли школы бахши (писарей), писавшие на уйгурском алфравите.

В Источниках произведений XIV-XV веков по отношению $к$ писарям на уйгурском письме применено слово бахши. В источнике приведены имена бахшил (Sodikov, 2000: 128). В письменных источниках XV-XVI веков, в частности в произведениях А^ишера Навои термин бахши в основном означает значение «котиб» (писарь), «мирзо» (работник канцеля-рии): «Бахши имеют авторитет срели тюрков, и сартам служат они»; «Бахши с утра $А$ вечера работает, знакомится с 
жалобами посетителей, некоторые жалобщики налоедают, и они хитростью от них избавляютсял (Alisher, 1965: 144).

Термин бахши и в произведении «Бабурнаме» употребляется в значении «котиб» (писарь), «мирзо» (работник канцелярии), «ёзувчи» (писатель): «Нахолившийся на ^олке бахши Султон Мухаммал приве^ ШамсилАина Мухаммеда нукера Холж и Ка^она. Из письма стало известна обстановка в Кабулел (р.129). В XVIII-XIX веках ^ексема бахши означала одну из Аолжностей в Бухарском ханстве, который ве^ учет средств, направленных на строительство (Majmagal-arkam, 1978: 94) В современном узбекском языке также имеется слово бахши, оно обозначает следующие значения: «1. Поэт, окин, поющий народные Аостаны. 2. Аекарь, который лечит разными причитаниями») (Uzbek explanatory dictionary, 1981: 86). ОтсюАа виАно, что только некоторые значения сохранились этого понятия, а значение «котиб» (писарь) вышло из употребления.

\section{Аитература / References}

Alisher, (1965). Alisher Ussentaev Works. 15 years. 6th Goodnight. - T., 1965 (In Tajik) / [А^ишер Навои. Асарлар. 15 жилА^и. 6-ж. Хайратул-аброр. - Т., 1965]

Ancient Turkish dictionary. (1969). Ancient Turkish dictionary. - Leningrad: Science. 1969 (In Russian) / [Аревнетюркский словарь. - ^енинграл: Наука. 1969]

Attuhfatuz, (1968). Attuhfatuz zakiyatu fillug'atit Turkey. - T. : Science, 1968 (In Uzbek) / Аттухфратуз закияту фриммуғатит туркия. - Т. : Фан, 1968

Bartold, V. (1990). V. until the invasion of Moĝol Turkestan. - Ankara, 1990 (In Turkish) / [Bartold V. V. Moĝol Istilasina Kadar Türkistan. - Ankara, 1990]

Borovkov, A. K. (1963). Lexicon of the Central Asian tefsir of the XII - XIII centuries. - M $\therefore$ Publishing house Vost. lit., 1963 (In Russian) / [Боровков А. К. Аексика Среднеазиатского тефрсира XII - XIII Вв. - М.: Иза-во Вост. Аит., 1963]

Eyuboğlu, (1995). Ismet Zeki Eyuboğlu. Etymology Dictionary of Turkish Language. Istanbul, Social Publications. - Istanbul, 1995 (In Turkish) / [Ismet Zeki Eyuboğlu. Türk Dilinin Etimoloji Sözlüğü. Istanbul, Sosyal Yayinlar. - Istanbul, 1995]

Gabain, (1974). A. von Gabain. Alttürkish Grammatik, 3. Auflage, Wiesbafen. 1974

Koshgariy, (1960). Mahmoud Koshgariy. Wall and Turkish Dictionary. It's three years. 1 yr T. : Science, 1960 (In Tajik/Russian) / [Mахмуд қошғарий. Аевону ^уғотит турк. Уч жилАли. 1-ж. - Т. : Фан, 1960] 
Majmagal-arkam, (1978). Majmagal-arkam (methods of documentation in Bukhara of the 18th century). - M.: Science, 1978 (In Russian) / [MaАжмa'a^-аркам (приемы Аокументации в Бухаре XУІІІ в.). - М.: Наука, 1978]

Polivanov, D. E. (1922). Far Eastern terms of writing tools // Collection of Turkestan Oriental Institute in honor of prof. A. E. Schmidt. - Tashkent, 1922 (In Russian) / [Поливанов А. Е. Аальневосточные термины орудий письма // Сборник Туркестанского Восточного института в честь профр. А. Э. ШмиАта. Ташкент, 1922]

Sherbak, A. M. (1962). Grammar of the Old Uzbek language. - M : Nauka, 1962 (In Russian/Uzbek) / [Шербак А. М. Грамматика староузбекского языка. - М.: Наука, 1962]

Sodikov, K. (2000). Turkic Mannavislik in History // Kadimghi Jászgorlik. - T.: Yuzuvchi, 2000 (In Kazakh) / [Содиқов Қ. Туркий матннавислик тарихидан // қалимги ёзма ёлгорлик^ар. - Т.: Ёзувчи, 2000]

Sultanov, I. I. (1987). Central Asian and East Turkestan late medieval manuscript book // Manuscript book in the culture of the peoples of the East. Book one. - $M$.: Nauka, 1987 (In Russian) / [Султанов И. И. Среднеазиатская и Восточнотуркестанская позднесредневековая рукописная книга // Рукописная книга в культуре народов Востока. Книга первая. - М.: Наука, 1987]

Tenishev, E. R. (1990). Uyghur dialect dictionary. - M .: Nauka, 1990 (In Russian) / [Тенишев Э. Р. Уйгурский Аиалектный словарь. - М.: Наука, 1990]

Turkish dictionary, (1988). Turkish dictionary. - Ankara: Turkish Language Institution Press House, 1988 (In Turkish) / [Türkçe Sözlük. - Ankara: Türk Dil Kurumu Basim Evi, 1988]

Uzbek Explanatory dictionary, (1981). Explanatory dictionary of the Uzbek language. - M.: Russian Language, 1981 (In Uzbek) / [Ўзбек тилининг изохли луғати. - М.: Рус ти^и, 1981] 


\section{КУАТУРНО-ИСТОРИЧЕСКО НАСАЕАСТВО: \\ ОПАЗВАНЕ, ПРЕАСТАВЯНЕ, АИГИТААИЗАЦИЯ}

\section{CULTURAL AND \\ HISTORICAL \\ HERITAGE}

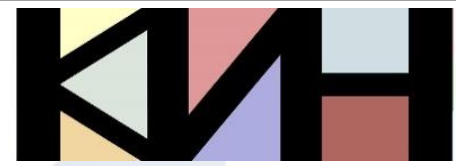

PRESERVATION

PRESENTATION

DIGITIZATION

\section{Съставители Editors \\ Галина БогАанова Galina Bogdanova \\ Ваня Матеева Vanya Mateeva}

Материалите в сборника са обект на авторско право. Разрешава се

безвьзмезАното ползване на техни електронни/ хартиени копия само за лична

употреба или обучение, при пьлно цитиране на текущата страница и слеА писмена Аекларация от цитиращия за Аипса на тьрговски намерения.

За копиране под Аруга фрорма, препубликуване или публикуване на сървъри се изисква писмено разрешение и/или заплащане.

() Авторски колектив, 2019

Технически реАактори:

Николай Ноев

Калина Сотирова-Вьлкова

Ка^оян Николов

This work is subject to copyright. Open and free of charge use of digital/hard copies of publications is granted only for personal or educational use, with full citation of the current page, and after written declaration of the quoting side for not-commercial Intention. For any other reproducing types, republishing, photocopying, recording, or any other storage retrieval system/ server written permission and/or fee is required.

(c) Authors`Group, 2019

Technical editors:

Nikolay Noev

Kalina Sotirova-Valkova

Kaloyan Nikolov

Научна поредица: том 5, брой 2 (7)/2019

Science series: vol. 5 , issue $2(7) / 2019$

www.math.bas.bg/vt/kin

ISSN: 2367-8038 